\title{
In Women with Symptoms of Cardiac Ischemia, Non-Obstructive Coronary Arteries, and Microvascular Dysfunction, ACE Inhibition is Associated with Improved Microvascular Function: A Double-blind Randomized Study from the NHLBI Women's Ischemia Syndrome Evaluation (WISE):
}

\author{
ACE-I Improves Microvascular Function in Women
}

Daniel F. Pauly, MD, PhDa , B. Delia Johnson, $\mathrm{PhD}^{\mathrm{c}}$, R. David Anderson, MDa, Eileen M. Handberg, PhDa , Karen M. Smith, MDa, Rhonda M. Cooper-DeHoff, PharmD, MS ${ }^{a, b}$, George Sopko, MD, MPH ${ }^{d}$, Barry M. Sharaf, MD $^{e}$, Sheryl F. Kelsey, PhD $^{c}$, C. Noel Bairey Merz, MD', and Carl J. Pepine, MDa

aDivision of Cardiovascular Medicine, University of Florida, Gainesville, FL

bDepartment of Pharmacotherapy and Translational Research, University of Florida, Gainesville, $\mathrm{FL}$

'Department of Epidemiology, University of Pittsburgh, Pittsburgh, PA

dNational Heart, Lung and Blood Institute, NIH, Bethesda, MD

eDivision of Cardiology, Rhode Island Hospital, Providence, RI

fHeart Institute, Cedars-Sinai Medical Center, Los Angeles, CA

\begin{abstract}
Background-We investigated the role of the renin-angiotensin system in women with signs and symptoms of ischemia without obstructive coronary artery disease (CAD). Although microvascular dysfunction has been suggested to explain this syndrome and recently was found to predict adverse outcomes, the mechanisms and treatments remain unclear.

Methods-In a substudy within the Women's Ischemia Syndrome Evaluation, 78 women with microvascular dysfunction (coronary flow reserve $[\mathrm{CFR}]<3.0$ following adenosine) and no
\end{abstract}

\footnotetext{
(C) 2011 Mosby, Inc. All rights reserved.

Correspondence: Carl J. Pepine, M.D., Division of Cardiovascular Medicine, University of Florida College of Medicine, P.O. Box 100277, Gainesville, FL32610 -0277. pepincj@ medicine.ufl.edu;(352)392-9082; Fax:(352) 371-0370.

Disclosures

This work was supported by contracts from the National Heart, Lung and Blood Institute, nos. N01-HV-68161, N01-HV-68162, N01HV-68163, N01-HV-68164, grants U0164829, U01 HL649141, U01 HL649241, a GCRC grant MO1-RR00425 from the National Center for Research Resources, and grants from the Gustavus and Louis Pfeiffer Research Foundation, Denville, New Jersey, Women's Guild of Cedars-Sinai Medical Center, Los Angeles, California, Ladies Hospital Aid Society of Western Pennsylvania, Pittsburgh, Pennsylvania, Pfizer Labs, and The Edythe L. Broad Endowment for Women's Heart Research, Los Angeles, California. Dr Pepine was funded, in part, from the Eminent Scholar Research Chair, AHA Suncoast Chapter; by NIH/NHLBI grants 5 U01 HL087366-04, 5 R01 HL091005-03, 5 R01 HL090957-03, 2 U01 GM074492-06, NIH/AG grant 3 U01 AG022376-05A2S1, and NIH/NCRR grant 5 UL1 RR029890-02; and a research grant from Pfizer Labs. The authors are solely responsible for the design and conduct of this study, including all study analyses, the drafting and editing of the paper, and its final content.

Publisher's Disclaimer: This is a PDF file of an unedited manuscript that has been accepted for publication. As a service to our customers we are providing this early version of the manuscript. The manuscript will undergo copyediting, typesetting, and review of the resulting proof before it is published in its final citable form. Please note that during the production process errors may be discovered which could affect the content, and all legal disclaimers that apply to the journal pertain.
} 
obstructive $\mathrm{CAD}$ were randomly assigned to either an angiotensin-converting enzyme inhibition (ACE-I) with quinapril or a placebo treatment group. The primary efficacy parameter was CFR at 16 weeks adjusted for baseline characteristics and clinical site. The secondary response variable was freedom from angina symptoms assessed using the Seattle Angina Questionnaire.

Results-A total of 61 women completed the 16-week treatment period with repeat CFR measurements, and treatment was well tolerated. For the primary outcome, at 16 weeks CFR improved more with ACE-I than placebo $(\mathrm{p}<0.02)$. For the secondary outcome of symptom improvement, ACE-I treatment $(\mathrm{p}=0.037)$ and CFR increase $(\mathrm{p}=0.008)$ both contributed.

Conclusions-Microvascular function improves with ACE-I therapy in women with signs and symptoms of ischemia without obstructive CAD. This improvement is associated with reduction in angina. The beneficial response of the coronary microvasculature was limited to women with lower baseline CFR values, suggesting that the renin-angiotensin system may be more involved among women with more severe microvascular defects.

\section{Introduction}

Women with symptoms and signs suggesting ischemia frequently seek medical care and have a low prevalence of obstructive coronary artery disease (CAD). ${ }^{1,2}$ Our understanding of pathologic mechanisms of ischemia without obstructive CAD is incomplete, leaving these women with few treatment options despite substantial utilization of medical resources ${ }^{3}$ and high cardiovascular event rates. ${ }^{3,4}$ One proposed mechanism is coronary microvascular dysfunction, ${ }^{5-8}$ which may contribute to poorer outcomes in women who later develop coronary obstruction.

There is growing interest in the coronary microvasculature as it affects clinical outcomes. ${ }^{9-11}$ Recently, we found that microvascular dysfunction predicted adverse outcomes in a cohort of women in the Women's Ischemia Syndrome Evaluation (WISE). ${ }^{12}$ Coronary resistance vessels are influenced by multiple factors including angiotensinconverting enzyme (ACE) and local angiotensin II (AT-II) levels. ${ }^{13,14}$ With hypertension, diabetes, or CAD, coronary flow reserve (CFR) measurements suggest acute and long-term improvement with ACE inhibition (ACE-I). ${ }^{15-20}$ These findings support the notion that blockade of the renin-angiotensin system (RAS) may regulate microvascular function in response to stressors, but existing studies were limited and provided mixed results. ${ }^{21-23}$

Accordingly, we hypothesized that ACE-I would improve coronary microvascular function and reduce symptoms in women with angina without angiographic obstruction. Quinapril was chosen for high tissue ACE-I activity and ability to improve vascular function in ischemic heart disease. ${ }^{24,25}$

\section{Methods}

The WISE is a National Heart, Lung and Blood Institute-sponsored project described in detail elsewhere. ${ }^{26}$ Briefly, women with signs and symptoms of ischemia referred for coronary angiography were screened. Accordingly, these women had chest pain, multiple $\mathrm{CAD}$ risk factors, and clinically ordered tests with evidence for ischemia. Institutional review boards at each site approved the protocol, written informed consent was obtained from each subject, and data were monitored by an independent data safety monitoring committee. This WISE substudy is registered at clinicaltrials.gov, NCT00150826.

\section{Patient selection and procedures}

Women aged 21-75 years were eligible if they had no coronary obstruction $\geq 50 \%$ and a CFR <3.0. Women were excluded if they were pregnant, breast feeding, unwilling to avoid 
pregnancy during the study; had acute coronary syndrome, uncontrolled hypertension, New York Heart Association class III or IV heart failure, ejection fraction $\leq 35 \%$, prior coronary bypass or percutaneous coronary intervention, uncorrected congenital or valvular heart disease, hypertrophic cardiomyopathy, significant lung or liver disease, serum creatinine $>3.0$, or coexisting illness with a likelihood of hospitalization or mortality within 6 months; recent alcoholism, cocaine, or amphetamine use; significant psychiatric disorder; or participation in another study. Subjects with history of angioedema or other hypersensitivity to ACE-I, who expressed unwillingness to participate in repeat invasive testing, or who had taken either an ACE-I or an AT-II receptor blocker within 30 days of planned enrollment were also excluded.

Baseline evaluation included comprehensive demographic and clinical data, clinical exam, and blood assays as described previously. ${ }^{26}$ Angina frequency was assessed from the angina frequency domain of the validated Seattle Angina Questionnaire (SAQ) ${ }^{27}$ Women underwent coronary angiography and CFR measurement. The CAD severity score was determined at the WISE Angiography Core Lab by assigning points for severity of stenosis, with weighting factors for proximal versus distal location and adjustments for collaterals when present. ${ }^{28}$

\section{CFR measurement}

Vasoactive medications were interrupted prior to CFR testing: long acting calcium antagonists for at least 48 hours; short acting calcium antagonists and long acting nitrates for at least 24 hours; and sublingual nitrates for at least 2 hours. CFR measurements were made using a Doppler-tipped guide wire and adenosine as described in detail elsewhere. ${ }^{12}$ Pulsedwave Doppler velocity recordings were analyzed by the WISE CFR core lab. The CFR was defined as the ratio of hyperemic time-averaged peak flow after adenosine to time-averaged peak flow at baseline, and the highest value among the repeated determinations was chosen. Core labs were masked to treatment assignment and clinical information.

\section{Randomization and drug titration}

Eligible subjects were randomly assigned in double-blind fashion to either ACE-I or placebo treatment group. Those assigned ACE-I started quinapril $40 \mathrm{mg} / \mathrm{d}$, and at the 1-week visit were titrated to $80 \mathrm{mg} / \mathrm{d}$. Those assigned placebo had similar dose escalation. Symptom questionnaires and exams were repeated at 4-week intervals. At 16 weeks, study drugs were discontinued for 48 hours to minimize blood pressure effects. Other vasoactive medications were withheld, and coronary angiography and CFR testing were repeated in a manner identical to the baseline study.

The primary efficacy parameter was CFR measured at 16 weeks, adjusted for baseline CFR, site, and clinical variables. The secondary response variable was the angina frequency subscore of the SAQ over time.

\section{Statistical analysis}

Sample size considerations-We hypothesized that the ACE-I group would have a higher CFR at 16 weeks compared to placebo. Prior WISE data indicated that similar women had a mean CFR of 3.0 with a standard deviation (SD) of 0.75. For the subgroup with $\mathrm{CFR}<3.0$, the mean CFR was 2.0 with an SD of 0.33. We therefore assumed that the CFR at 16 weeks would have an intermediate SD of 0.60 . We considered a CFR difference between treatment groups of $20 \%$ to be clinically important. A sample size of 30 per group (total 60) was calculated as adequate to detect this difference with a power of 0.80 . Assuming a 20\% dropout rate, enrollment was set at 78 patients to reach 60 completed patients. 
Statistical methods-Pertinent baseline characteristics were tabulated overall and by treatment group. Continuous variables were summarized as mean $\pm \mathrm{SD}$ or as median values with interquartile ranges. Categorical variables were presented as percentages. The CFR was analyzed as described in previous WISE reports ${ }^{12}$ and elsewhere ${ }^{29,30}$ using adjusted ANOVA involving four steps. ${ }^{31}$ The first involved stepwise modeling to develop the best predictive model of log CFR at week 16 and included baseline CFR and other variables with weak univariate associations $(\mathrm{p}<0.20)$ in preliminary analysis. Inclusion of baseline CFR is more precise than measuring residual change as the outcome. Clinical site-specific stratifying variables were included, and site-by-treatment interaction terms were evaluated to determine if treatment effect varied across sites. Treatment group was not included in this initial model but was then added to the model as step 2 . A treatment group by baseline log CFR interaction term was fitted in the model as step 3. For each step, a semi-partial correlation was generated and tested. The final model was reported in step 4, and describes each variable separately relative to other variables as predictors of treatment effect.

Angina frequency SAQ subscale data, collected at each study visit, were analyzed with repeated measures analysis (PROC MIXED) to assess angina frequency change over time. An unstructured covariance model was fitted. Fixed effects included treatment group and CFR change (baseline to 16 weeks). Due to primary interest in change from baseline, baseline SAQ angina score was entered as a fixed effect. Other potential covariates included site, site by treatment interaction terms, and relevant baseline characteristics. Study visit and a treatment group by visit interaction term were entered as random effects.

A p-value of 0.05 was considered statistically significant. All analyses were performed using SAS, Version 9.1 (SAS Institute, Cary, NC).

\section{Results}

Of the 78 women randomly assigned to treatment, 61 completed the 16-week angiogram, CFR measurement, and angina assessments: 29 were in the ACE-I group and 32 in the placebo group. Treatment was well tolerated. One patient discontinued prematurely for suspected drug-related reasons: she developed periorbital edema and upon unblinding was receiving placebo. Other reasons for discontinuation were related to refusal to continue with follow-up visits and/or repeat catheterization at 16 weeks. Treatment groups were reasonably well-matched (Table I), but the ACE-I group trended to be older, have lower BMI, to be less likely to smoke, less likely to use nitrates ( $\mathrm{p}=0.02$ ), and have CFR 2.5.

For the primary outcome, at 16 weeks CFR improved more with ACE-I than placebo $(\mathrm{p}<0.019)$ (Figure 1, Table II). The $\mathrm{p}$ value corresponds to a treatment by baseline interaction, adjusted for baseline CFR, diabetes history, and clinical site. Women with the lowest baseline CFR (e.g. $\leq 2.5$ ) improved the most with ACE-I (Figure 1, Table III).

CFR, unadjusted, improved in both treatment arms: at 16 weeks CFR was $2.72 \pm 0.48$ in the placebo group and $2.77 \pm 0.50$ in the ACE-I group $(\mathrm{p}=0.79)$. Correlation between baseline CFR and 16 week CFR was 0.62 for the placebo group, suggesting that 16 week values were strongly driven by baseline values. For the ACE-I treatment group, the correlation between baseline CFR and 16 week CFR was 0.18, suggesting that factors other than baseline values contributed to the 16 week values (Figure 1). The significant baseline CFR by treatment group interaction term $(\mathrm{p}=0.019$, Table II) indicates a substantive difference between the two slopes. 


\section{Multivariable Predictors of CFR at 16 weeks}

Treatment with ACE-I significantly influenced systolic blood pressure (SBP) at 16 weeks (126 $\pm 15 \mathrm{~mm} \mathrm{Hg}$ to $120 \pm 16$ ) versus placebo (126 $\pm 22 \mathrm{~mm} \mathrm{Hg}$ to $125 \pm 18$ ) which persisted ( $\mathrm{p}=0.038$ ) after adjustment for age, BMI, and current hormone replacement use. Diastolic blood pressure and heart rate were not significantly different in either group comparing baseline and 16 weeks.

Three hierarchical models were developed for CFR at 16 weeks (Table II). Model 1 is the final multivariable predictive model of 16 week CFR that does not include the treatment effect. Significant independent predictors of higher 16 week CFR were higher baseline CFR, lower 16 week SBP, absence of diabetes and clinical site. Although not an independent predictor of 16 week CFR, baseline HDL-C was an effect moderator and therefore was retained in the model. A clinical site by treatment interaction term was not statistically significant ( $\mathrm{p}=0.98$, not shown). Model 1 predicted $34 \%$ of total variance $\left(\mathrm{R}^{2}\right)$ in 16 week CFR. Adding treatment group (Model 2) increased total $\mathrm{R}^{2}$ by $0.021(\mathrm{p}=0.19)$, and adding a treatment by baseline CFR interaction term (Model 3) increased $R^{2}$ by $0.068(\mathrm{p}=0.019)$. No other variables or interaction terms were independent predictors or effect moderators of 16 week CFR (Table II).

\section{Differential change in CFR across baseline CFR values}

The finding of a statistically significant baseline CFR by treatment-group interaction term indicates the presence of a differential treatment effect that depends on baseline CFR. This differential effect is illustrated by further stratifying by baseline $\mathrm{CFR} \leq 2.5$ versus $\mathrm{CFR}>2.5$, generally considered the threshold for "suboptimal" CFR from outcome trials ${ }^{29}$. The three measures summarized in Table III are CFR at 16 weeks, CFR change from baseline to 16 weeks (difference between these values), and percentage of women with an increase in CFR of $>0.4$, or a $16 \%$ improvement. Consistently, subjects in the ACE-I group with baseline CFR $\leq 2.5$ showed the greatest increase in CFR at 16 weeks, and $62 \%$ of these women had a CFR increase of $>0.4(p=0.03$, Table III).

\section{Secondary Outcome: Symptom Improvement}

In the SAQ angina frequency subscale, a higher score signifies more freedom from angina. The ACE-I treatment was associated with improved $(\mathrm{p}=0.037)$ angina frequency versus placebo (Figure 2, Table IV). At baseline, mean SAQ angina scores were similar comparing treatment groups. At 4 weeks, these scores had increased (improved) by almost 20 points in the ACE-I group and remained at that level for the duration of the trial (regression slope from baseline to 16 weeks: $\beta=0.11, p=0.0003$ ). Improvement was also noted for the placebo group, suggesting a placebo effect, however this was gradual and remained at least 10 points below that of the ACE-I group (regression slope: $\beta=0.07, p=0.02$ ). Multivariable modeling (Table IV) identified ACE-I treatment group ( $\mathrm{p}=0.037)$, study visit $(\mathrm{p}=0.016)$, and lower baseline freedom from angina $(\mathrm{p}<0.0001)$ as significant independent predictors of improved follow-up angina score (Table IV). Additionally, CFR improvement (baseline to 16 weeks treatment) was a strong independent predictor of freedom from angina $(\mathrm{p}=0.008)$. A baseline angina frequency by visit interaction term was not significant. No other baseline variables, change in SBP, or interactions were independent covariates to modulate treatment effect (data not shown).

\section{Discussion}

Treatment options for women with disabling angina and microvascular dysfunction in the absence of coronary stenosis present a challenge. While risk factor modification has been promoted, little is known about whether this leads to improvement in microvascular function 
or suppression of symptoms. In the absence of large artery obstruction, other components of coronary vascular disease may contribute to ischemia, including a microvascular component, which is well documented with hypertension, dyslipidemia, or insulin resistance states. ${ }^{32,33}$ With hypertension and/or diabetes, improvement in microvascular function has been reported with ACE- ${ }^{15-20}$ suggesting a role for the RAS. These conditions are highly prevalent among older women, as estrogen depletion is associated with increases in angiotensin $\mathrm{AT}_{1}$ receptor binding ${ }^{34}$, direct transcriptional effects on brain angiotensinogen production ${ }^{35}$, and upregulation of tumor necrosis factor-alpha ${ }^{36}$ and kidney angiotensin $\mathrm{AT}_{2}$ receptors. ${ }^{37}$ Sex differences in the RAS which alter microvascular responses to AT-II or RAS inhibitors have also been described. ${ }^{38}$

Our results provide evidence for a beneficial effect of ACE-I in women with angina without obstructive CAD who have coronary microvascular dysfunction. While ACE-I was associated with higher CFR at 16 weeks, the effects concentrated among women with more severe baseline CFR impairment. Diabetes, baseline CFR, and site-specific variables also contributed to the CFR response. Regression to the mean was a likely explanation for improvement in the placebo group which was more pronounced among women with lower baseline CFR. However, the significant baseline CFR by treatment group interaction term $(\mathrm{p}=0.019$, Table II) indicates a substantive difference between the two slopes, and represents the incremental effect of ACE-I treatment effect over and above regression to the mean. The beneficial effect of ACE-I and improvement of CFR were linked to reduced angina frequency. These findings suggest an ACE-I treatment-specific effect, as well as a microvascular effect, since improvement of microvascular function appeared directly linked to symptom improvement.

Our results confirm and extend the limited data available on blocking effects of AT-II in microvascular angina among women. Kaski and colleagues ${ }^{21}$, in a randomized, single-blind, crossover study of 10 patients ( 7 women), found after 2 weeks of enalapril (10 mg/d) versus placebo that exercise duration and time to ischemia increased as ST depression decreased. Chen and coworkers ${ }^{22}$ studied 20 patients (5 women) randomized to enalapril (5 mg twice daily, $n=10)$ or placebo $(n=10)$ (double-blind design). After 8 weeks, exercise duration and CFR improved as plasma von Willebrand factor and nitric oxide increased with enalapril versus placebo. But Russell et $\mathrm{al}^{23}$ studied 24 patients ( 21 women) (randomized, doubleblind, two-period crossover) with treatment periods of only 3 weeks with either irbesartan $(300 \mathrm{mg} / \mathrm{day})$ or placebo. Exercise duration significantly increased during placebo, and other measures were not significantly changed with irbesartan. However, the definition of "microvascular angina" was based on perfusion defects rather than reduced CFR by intracoronary Doppler as in other reports. ${ }^{21,22}$

Some limitations deserve consideration. Although appropriately powered for the primary outcome, this study was underpowered for angina frequency, due to wide individual variability over time and the well known placebo effect. While we observed reduction in angina after starting both placebo and ACE-I, the reduction in angina among those assigned ACE-I was more pronounced in magnitude and duration versus placebo. The $18 \mu \mathrm{g}$ dose of intracoronary adenosine is lower than doses currently used to cause maximal vasodilatation for fractional flow reserve measurements and thus may not have achieved maximal hyperemia in every patient. Similar intracoronary adenosine doses have been used in studies linking lower CFR with adverse outcome. ${ }^{12,29,30}$ Future studies should further clarify the role of ACE-I on long-term outcome as this may provide a rationale, other than improvement in microvascular function or symptoms, for using ACE-I in women without obstructive CAD. It should also be noted that this study was not powered to detect differences in subgroups, so the subgroup findings are considered exploratory. 


\section{Conclusions}

Our findings indicate that microvascular dysfunction is responsive to ACE-I therapy in women with signs and symptoms of ischemia without angiographic obstructive CAD. This benefit was limited to women with CFR values $\leq 2.5$, generally considered the threshold for the most severe microvascular limitation.

\section{References}

1. Shaw LJ, Shaw RE, Merz CN, et al. Impact of ethnicity and gender differences on angiographic coronary artery disease prevalence and in-hospital mortality in the American College of CardiologyNational Cardiovascular Data Registry. Circulation. 2008; 117:1787-801. [PubMed: 18378615]

2. Anderson RD, Pepine CJ. Gender differences in the treatment for acute myocardial infarction: bias or biology? Circulation. 2007; 115:823-6. [PubMed: 17309930]

3. Shaw LJ, Merz CN, Pepine CJ, et al. The economic burden of angina in women with suspected ischemic heart disease: results from the National Institutes of Health--National Heart, Lung, and Blood Institute--sponsored Women's Ischemia Syndrome Evaluation. Circulation. 2006; 114:894904. [PubMed: 16923752]

4. Johnson BD, Shaw LJ, Pepine CJ, et al. Persistent chest pain predicts cardiovascular events in women without obstructive coronary artery disease: results from the NIH-NHLBI-sponsored Women's Ischaemia Syndrome Evaluation (WISE) study. Eur Heart J. 2006; 27:1408-15. [PubMed: 16720691]

5. Cannon RO 3rd, Watson RM, Rosing DR, et al. Angina caused by reduced vasodilator reserve of the small coronary arteries. J Am Coll Cardiol. 1983; 1:1359-73. [PubMed: 6853894]

6. Chauhan A, Mullins PA, Taylor G, et al. Both endothelium-dependent and endothelium-independent function is impaired in patients with angina pectoris and normal coronary angiograms. Eur Heart J. 1997; 18:60-8. [PubMed: 9049516]

7. Panting JR, Gatehouse PD, Yang GZ, et al. Abnormal subendocardial perfusion in cardiac syndrome $\mathrm{X}$ detected by cardiovascular magnetic resonance imaging. N Engl J Med. 2002; 346:1948-53. [PubMed: 12075055]

8. Reis SE, Holubkov R, Conrad Smith AJ, et al. Coronary microvascular dysfunction is highly prevalent in women with chest pain in the absence of coronary artery disease: results from the NHLBI WISE study. Am Heart J. 2001; 141:735-41. [PubMed: 11320360]

9. Camici PG, Crea F. Coronary microvascular dysfunction. N Engl J Med. 2007; 356:830-40. [PubMed: 17314342]

10. Gibson CM, Cannon CP, Murphy SA, et al. Relationship of the TIMI myocardial perfusion grades, flow grades, frame count, and percutaneous coronary intervention to long-term outcomes after thrombolytic administration in acute myocardial infarction. Circulation. 2002; 105:1909-13. [PubMed: 11997276]

11. Fearon WF, Aarnoudse W, Pijls NH, et al. Microvascular resistance is not influenced by epicardial coronary artery stenosis severity: experimental validation. Circulation. 2004; 109:2269-72. [PubMed: 15136503]

12. Pepine CJ, Anderson RD, Sharaf BL, et al. Coronary microvascular reactivity to adenosine predicts adverse outcome in women evaluated for suspected ischemia results from the National Heart, Lung and Blood Institute WISE (Women's Ischemia Syndrome Evaluation) study. J Am Coll Cardiol. 2010; 55:2825-32. [PubMed: 20579539]

13. Dzau VJ. Theodore Cooper Lecture: Tissue angiotensin and pathobiology of vascular disease: a unifying hypothesis. Hypertension. 2001; 37:1047-52. [PubMed: 11304501]

14. Banes-Berceli AK, Ketsawatsomkron P, Ogbi S, et al. Angiotensin II and endothelin-1 augment the vascular complications of diabetes via JAK2 activation. Am J Physiol Heart Circ Physiol. 2007; 293:H1291-9. [PubMed: 17526654]

15. Antony I, Lerebours G, Nitenberg A. Angiotensin-converting enzyme inhibition restores flowdependent and cold pressor test-induced dilations in coronary arteries of hypertensive patients. Circulation. 1996; 94:3115-22. [PubMed: 8989118] 
16. Motz W, Strauer BE. Improvement of coronary flow reserve after long-term therapy with enalapril. Hypertension. 1996; 27:1031-8. [PubMed: 8621193]

17. Rizzoni D, Muiesan ML, Porteri E, et al. Effects of long-term antihypertensive treatment with lisinopril on resistance arteries in hypertensive patients with left ventricular hypertrophy. J Hypertens. 1997; 15:197-204. [PubMed: 9469796]

18. Giugliano D, Marfella R, Acampora R, et al. Effects of perindopril and carvedilol on endotheliumdependent vascular functions in patients with diabetes and hypertension. Diabetes Care. 1998; 21:631-6. [PubMed: 9571355]

19. Higuchi T, Abletshauser C, Nekolla SG, et al. Effect of the angiotensin receptor blocker Valsartan on coronary microvascular flow reserve in moderately hypertensive patients with stable coronary artery disease. Microcirculation. 2007; 14:805-12. [PubMed: 17907015]

20. Parodi O, Neglia D, Sambuceti G, et al. Regional myocardial blood flow and coronary reserve in hypertensive patients. The effect of therapy. Drugs. 1992; 44 (Suppl 1):48-55. [PubMed: 1283584]

21. Kaski JC, Rosano G, Gavrielides S, et al. Effects of angiotensin-converting enzyme inhibition on exercise-induced angina and ST segment depression in patients with microvascular angina. $\mathrm{J}$ Am Coll Cardiol. 1994; 23:652-7. [PubMed: 8113548]

22. Chen JW, Hsu NW, Wu TC, et al. Long-term angiotensin-converting enzyme inhibition reduces plasma asymmetric dimethylarginine and improves endothelial nitric oxide bioavailability and coronary microvascular function in patients with syndrome X. Am J Cardiol. 2002; 90:974-82. [PubMed: 12398965]

23. Russell SJ, Di Stefano EM, Naffati MT, et al. The effects of the angiotensin II receptor (type I) antagonist irbesartan in patients with cardiac syndrome X. Heart. 2007; 93:253-4. [PubMed: 17228077]

24. Mancini GB, Henry GC, Macaya C, et al. Angiotensin-converting enzyme inhibition with quinapril improves endothelial vasomotor dysfunction in patients with coronary artery disease. The TREND (Trial on Reversing ENdothelial Dysfunction) Study. Circulation. 1996; 94:258-65. [PubMed: 8759064]

25. Anderson TJ, Elstein E, Haber H, et al. Comparative study of ACE-inhibition, angiotensin II antagonism, and calcium channel blockade on flow-mediated vasodilation in patients with coronary disease (BANFF study). J Am Coll Cardiol. 2000; 35:60-6. [PubMed: 10636260]

26. Merz CN, Kelsey SF, Pepine CJ, et al. The Women's Ischemia Syndrome Evaluation (WISE) study: protocol design, methodology and feasibility report. J Am Coll Cardiol. 1999; 33:1453-61. [PubMed: 10334408]

27. Spertus JA, Winder JA, Dewhurst TA, et al. Development and evaluation of the Seattle Angina Questionnaire: a new functional status measure for coronary artery disease. J Am Coll Cardiol. 1995; 25:333-41. [PubMed: 7829785]

28. Sharaf BL, Pepine CJ, Kerensky RA, et al. Detailed angiographic analysis of women with suspected ischemic chest pain (pilot phase data from the NHLBI-sponsored Women's Ischemia Syndrome Evaluation [WISE] Study Angiographic Core Laboratory). Am J Cardiol. 2001; 87:937-41. [PubMed: 11305981]

29. Albertal M, Voskuil M, Piek JJ, et al. Coronary flow velocity reserve after percutaneous interventions is predictive of periprocedural outcome. Circulation. 2002; 105:1573-8. [PubMed: 11927525]

30. Serruys PW, di Mario C, Piek J, et al. Prognostic Value of Intracoronary Flow Velocity and Diameter Stenosis in Assessing the Short- and Long-term Outcomes of Coronary Balloon Angioplasty : The DEBATE Study (Doppler Endpoints Balloon Angioplasty Trial Europe). Circulation. 1997; 96:3369-77. [PubMed: 9396429]

31. Muller, K.; Fetterman, B. Regression and ANOVA: An Integrated Approach Using SAS Software. Hoboken, NJ: Wiley; 2003.

32. Orasanu G, Plutzky J. The pathologic continuum of diabetic vascular disease. J Am Coll Cardiol. 2009; 53:S35-42. [PubMed: 19179216]

33. Schelbert HR. Coronary circulatory function abnormalities in insulin resistance: insights from positron emission tomography. J Am Coll Cardiol. 2009; 53:S3-8. [PubMed: 19179215] 
34. Harrison-Bernard LM. Targeting of the renin-Angiotensin system as an adjunct to estrogen replacement therapy. Hypertension. 2004; 44:390-1. [PubMed: 15337737]

35. Greenland KJ, Sernia C. Oestrogenic regulation of brain angiotensinogen. J Neuroendocrinol. 2004; 16:508-15. [PubMed: 15189325]

36. Arenas IA, Armstrong SJ, Xu Y, et al. Tumor necrosis factor-alpha and vascular angiotensin II in estrogen-deficient rats. Hypertension. 2006; 48:497-503. [PubMed: 16864744]

37. Armando I, Jezova M, Juorio AV, et al. Estrogen upregulates renal angiotensin II AT(2) receptors. Am J Physiol Renal Physiol. 2002; 283:F934-43. [PubMed: 12372768]

38. Sartori-Valinotti JC, Iliescu R, Yanes LL, et al. Sex differences in the pressor response to angiotensin II when the endogenous renin-angiotensin system is blocked. Hypertension. 2008; 51:1170-6. [PubMed: 18259017] 


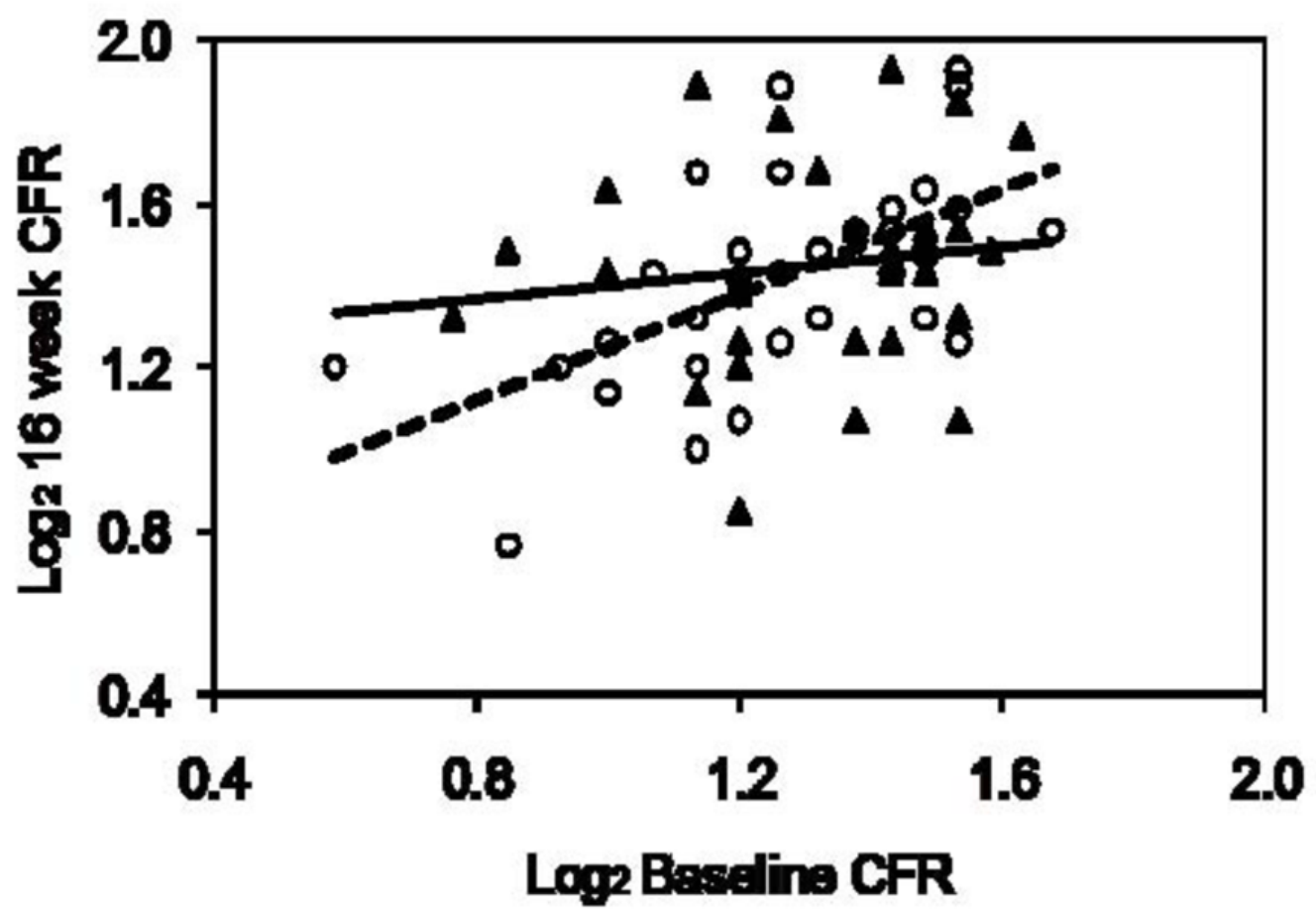

Figure 1.

Relationship between $(\log 2)$ coronary flow reserve (CFR) at 16 weeks and $(\log 2)$ CFR at baseline stratified by treatment group: ACE-I group (shown as triangle and solid line); placebo group (shown as circle and dashed line). The regression lines were derived from the model summarized in Table I: the placebo group regression line is not different from the line of identity, whereas the ACE-I group regression line is significantly different $(\mathrm{p}=0.019)$. A point on this $\log 2$ scale of 1 represents an actual CFR of 2.0 and a point of 2 represents a CFR of 4.0. ACE-I, angiotensin-converting enzyme inhibition. 


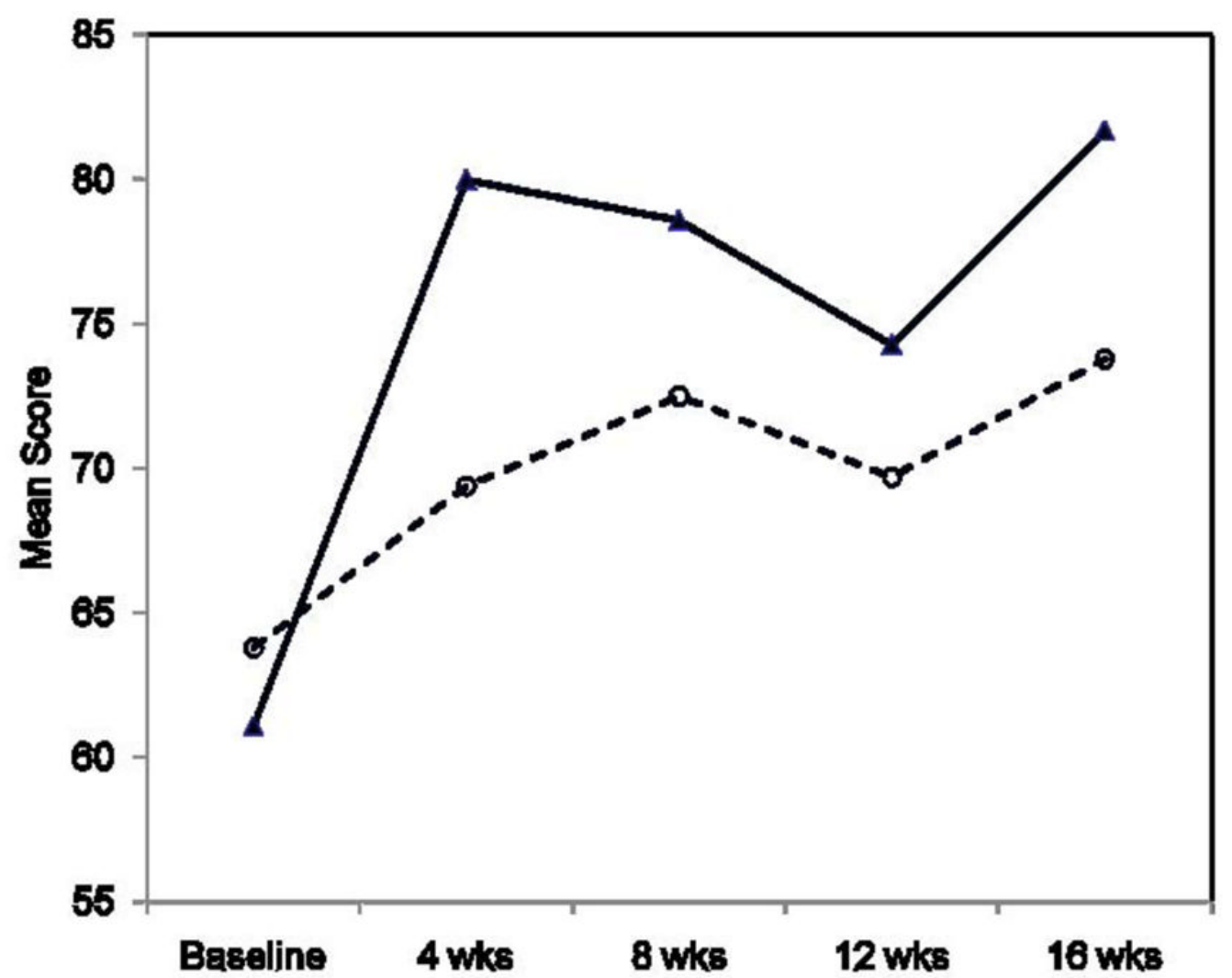

Figure 2.

Mean angina frequency score (Seattle Angina Questionnaire [SAQ]) over time by treatment group. At baseline, mean SAQ angina scores were similar comparing treatment groups. At 4 weeks, scores improved more in the ACE-I group, and this finding persisted to 16 weeks. Beta coefficients (standard errors): ACE-I group (triangle and solid line) $\beta=0.11(0.03)$, $\mathrm{p}=0.0003$; placebo group (circle and dashed line) $\beta=0.07(0.03), \mathrm{p}=0.02$. Note that higher SAQ angina score indicates decreased angina frequency (or greater freedom from angina). $A C E-I$, angiotensin-converting enzyme inhibition. 
Table I

Baseline characteristics

\begin{tabular}{|c|c|c|c|c|}
\hline Baseline & $\begin{array}{c}\text { Overall } \\
\mathrm{n}=61\end{array}$ & $\begin{array}{c}\begin{array}{c}\text { Placebo } \\
\mathrm{n}=32\end{array} \\
\text {. }\end{array}$ & $\begin{array}{c}\text { ACE-I } \\
\mathbf{n}=29\end{array}$ & $\mathbf{p}^{*}$ \\
\hline Baseline CFR (mean $\pm \mathrm{SD})$ & $2.48 \pm 0.37$ & $2.44 \pm 0.38$ & $2.52 \pm 0.36$ & 0.44 \\
\hline Baseline CFR $\leq 2.5(\%)$ & 52 & 59 & 45 & 0.26 \\
\hline \multicolumn{5}{|l|}{ Angiographic Findings: } \\
\hline CAD severity score (mean $\pm \mathrm{SD}$ ) & $6.2 \pm 2.4$ & $6.6 \pm 3.0$ & $5.9 \pm 1.4$ & 0.45 \\
\hline Stenosis $\geq 20 \%$ in any vessel $(\%)$ & 38 & 41 & 35 & 0.72 \\
\hline $\mathrm{LV}$ ejection fraction (mean $\pm \mathrm{SD}$ ) & $69 \pm 9$ & $68 \pm 10$ & $69 \pm 8$ & 0.91 \\
\hline \multicolumn{5}{|l|}{ Demographics: } \\
\hline Age, years (mean $\pm \mathrm{SD})$ & $54 \pm 10$ & $51 \pm 10$ & $56 \pm 8$ & 0.09 \\
\hline Racial minority (\%) & 8 & 9 & 7 & 0.99 \\
\hline \multicolumn{5}{|l|}{ CAD Risk Factors: } \\
\hline $\mathrm{BMI}\left(\mathrm{kg} / \mathrm{m}^{2}\right)($ mean $\pm \mathrm{SD})$ & $31.2 \pm 7.4$ & $32.9 \pm 8.3$ & $29.4 \pm 5.7$ & 0.08 \\
\hline Obesity $($ BMI $\geq 30)(\%)$ & 47 & 55 & 38 & 0.19 \\
\hline Waist circumf., inches (mean $\pm \mathrm{SD}$ ) & $37.3 \pm 5.9$ & $38.4 \pm 6.1$ & $36.1 \pm 5.5$ & 0.18 \\
\hline Waist/hip ratio (mean $\pm \mathrm{SD})$ & $0.83 \pm 0.07$ & $0.85 \pm 0.07$ & $0.81 \pm 0.07$ & 0.17 \\
\hline $\mathrm{SBP}(\mathrm{mmHg})($ mean $\pm \mathrm{SD})$ & $126 \pm 19$ & $126 \pm 22$ & $126 \pm 15$ & 0.64 \\
\hline $\mathrm{DBP}(\mathrm{mmHg})($ mean $\pm \mathrm{SD})$ & $75 \pm 10$ & $76 \pm 11$ & $73 \pm 8$ & 0.33 \\
\hline Heart rate (beats/min) $($ mean $\pm \mathrm{SD})$ & $73 \pm 12$ & $74 \pm 12$ & $72 \pm 12$ & 0.47 \\
\hline Family history of premature CAD $(\%)$ & 45 & 38 & 54 & 0.21 \\
\hline Functional capacity (DASI) $($ mean \pm SD) & $25.9 \pm 15.7$ & $25.8 \pm 16.1$ & $26.1 \pm 15.5$ & 0.81 \\
\hline Self-report of high stress lifestyle (\%) & 26 & 31 & 21 & 0.35 \\
\hline \multicolumn{5}{|l|}{ History of $(\%)$ : } \\
\hline Diabetes & 11 & 6 & 17 & 0.24 \\
\hline Hypertension & 39 & 44 & 34 & 0.46 \\
\hline Dyslipidemia & 53 & 45 & 61 & 0.23 \\
\hline Current smoking & 15 & 22 & 7 & 0.15 \\
\hline Ever smoking & 46 & 56 & 34 & 0.09 \\
\hline \multicolumn{5}{|l|}{ Current Medication Use (\%): } \\
\hline Statins & 33 & 34 & 31 & 0.78 \\
\hline Diuretics & 23 & 22 & 24 & 0.83 \\
\hline Beta-blockers & 43 & 47 & 38 & 0.48 \\
\hline Calcium antagonists & 26 & 28 & 24 & 0.72 \\
\hline Nitrates & 31 & 44 & 17 & 0.02 \\
\hline Thyroid replacement & 23 & 25 & 21 & 0.69 \\
\hline Psychotropic medications & 49 & 41 & 59 & 0.16 \\
\hline Hormone therapy & 30 & 25 & 36 & 0.37 \\
\hline
\end{tabular}

$A C E-I$, angiotensin-converting enzyme inhibition; $C F R$, coronary flow reserve; $S D$, standard deviation; $C A D$, coronary artery disease; $L V$, left ventricle; $B M I$, body mass index; $S B P$, systolic blood pressure; $D B P$, diastolic blood pressure; $D A S I$, Duke Activity Status Index.

* p-values by Kruskal-Wallis nonparametric statistic for continuous variables and chi square for dichotomous variables. 
Table II

Multivariable prediction of CFR at 16 weeks

\begin{tabular}{l|l|c|c|c}
\hline Model & Variables in the Model & Beta (SE) & p-Value & $\begin{array}{c}\text { Model } \mathbf{R}^{\mathbf{2}} \\
\left.\text { (p-value for } \Delta \mathbf{R}^{2}\right)\end{array}$ \\
\hline 1 & Baseline CFR & $0.35(0.13)$ & 0.010 & \\
& SBP at 16 weeks & $-0.023(0.013)$ & 0.09 & \\
& Diabetes & $-0.13(0.06)$ & 0.048 & \\
& Baseline HDL & $0.016(0.014)$ & 0.26 & \\
& Clinical Site 1* & $0.20(0.06)$ & 0.004 & \\
\hline & Clinical Site 2* & $0.15(0.07)$ & 0.046 & $0.343(0.0009)$ \\
\hline 2 & Treatment Group & $0.06(0.04)$ & 0.19 & $0.364(0.19)$ \\
\hline 3 & Treatment Group x Baseline CFR & $-0.62(0.25)$ & 0.019 & $0.433(0.019)$ \\
\hline
\end{tabular}

$C F R$, coronary flow reserve; $S E$, standard error; $S B P$, systolic blood pressure; $H D L$, high-density lipoprotein cholesterol.

Diabetes: $1=$ history of diabetes, $0=$ no history of diabetes; Treatment group: $1=A C E-I, 0=$ placebo.

No other variables added significantly to the model among age, BMI, diastolic BP, heart rate, hypertension, smoking, hormone replacement therapy, statin use, CAD severity score, nitrate use, or clinical site by treatment group interaction.

Clinical site 3 as reference group 


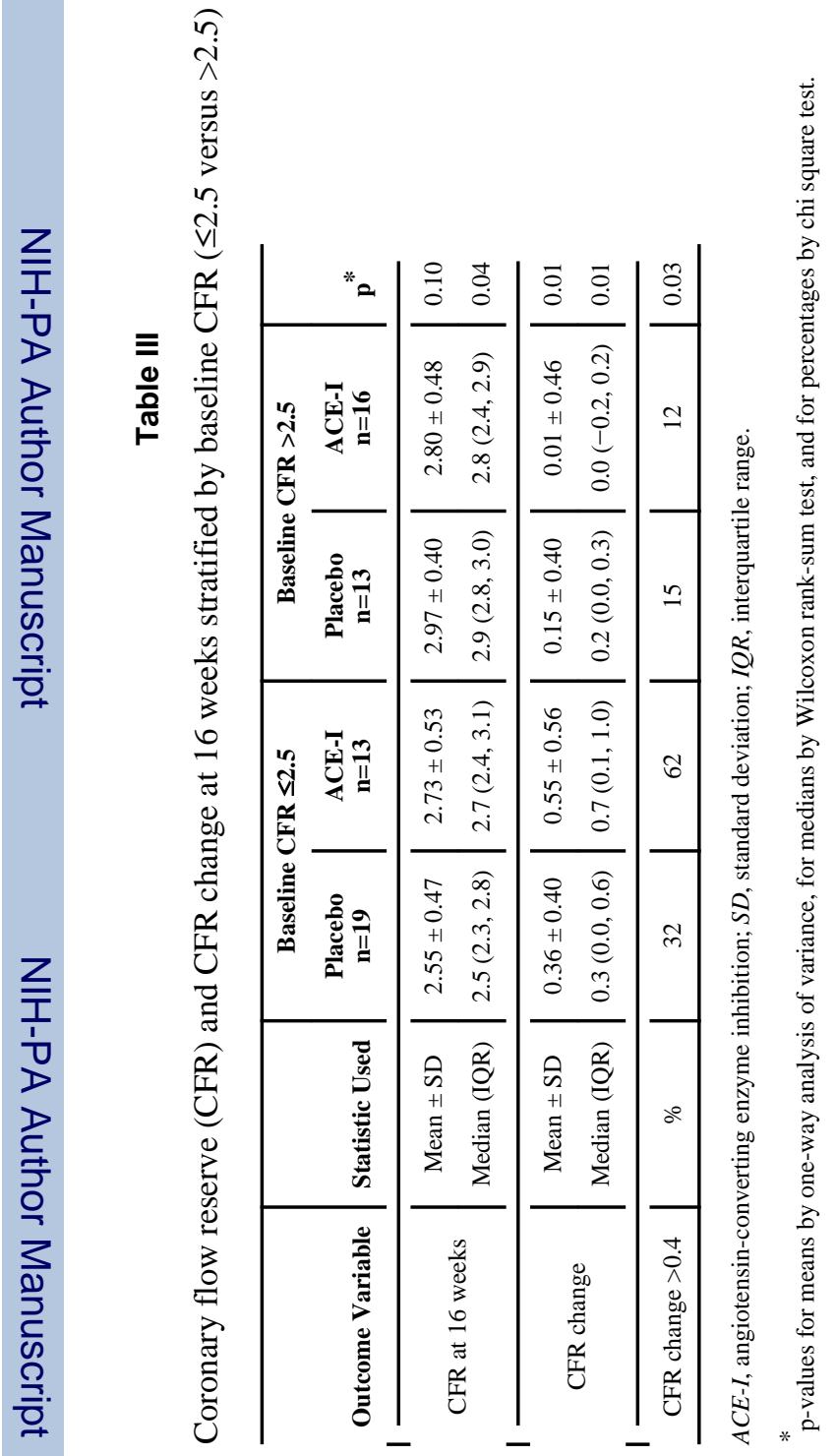


Table IV

Independent predictors of freedom from angina over follow-up visits

\begin{tabular}{lcc}
\hline Predictor & Beta (SE) & p \\
\hline Treatment group & $8.75(4.08)$ & 0.037 \\
Visit & $*$ & 0.016 \\
Baseline SAQ angina frequency score & $0.38(0.09)$ & $<0.0001$ \\
CFR change & $9.83(3.50)$ & 0.008 \\
Age (years) & $0.08(0.20)$ & 0.70 \\
\hline
\end{tabular}

* Since Visit was entered as a categorical random effect, no parameter estimate was generated. SE, standard error; $S A Q$, Seattle Angina Questionnaire (higher score=more freedom from angina); $C F R$, coronary flow reserve.

Treatment group: $1=$ ACE-I, $0=$ placebo. CFR change defined as CFR at 16 weeks minus CFR at baseline.

No other variables entered the model among body mass index, systolic blood pressure, diastolic blood pressure, heart rate, history of hypertension, diabetes, current or ever smoking, hormone replacement therapy, high-density lipoprotein cholesterol, CAD severity score, change in systolic blood pressure, and interaction effects. 